\title{
OCORRÊNCIAS ÉTICAS EM AMBIENTE HOSPITALAR E AS PERCEPÇÕES DOS PROFISSIONAIS
}

\author{
Camila Pasetto ${ }^{1}$, Solange Rothbarth ${ }^{2}$
}

\begin{abstract}
RESUMO: O ambiente hospitalar possui, em sua particularidade, tensão natural devido ao delicado fato de trabalhar com a complexidade que abrange a vida e a morte. Deste modo, destaca-se a importância de cuidados relacionados à ética e ao sigilo profissional, considerando que descuidos com tais questões podem agravar a tensão existente na hospitalização. Objetivou-se com esta pesquisa desvendar as percepções de chefias de áreas e setores a respeito de ocorrências éticas no ambiente hospitalar. Utilizando-se abordagem qualitativa foram aplicados questionários abertos a 13 chefias de setores de um hospital infantil, entre agosto e setembro de 2011, que originaram quatro categorias de análise: Conceituações despercebidas na prática; Infrações da equipe de saúde; Implicações para os pacientes e seus acompanhantes; e Sugestões e responsabilidades. Vislumbrou-se com a pesquisa reflexões e propostas de ações educativas, pautadas em ética e sigilo profissional, com vistas a aprimorar o atendimento hospitalizar.
\end{abstract}

PALAVRAS-CHAVE: Ética; Hospitalização; Pessoal de saúde.

\section{ETHICAL OCCURRENCES IN THE HOSPITAL SETTING AND THE PROFESSIONALS' PERCEPTIONS}

\begin{abstract}
The hospital environment possesses, as part of its nature, natural tension due to the delicate fact of working with the complexity which encompasses life and death. Therefore the importance of care related to ethics and to professional confidentiality stands out, considering that negligence with such questions can worsen the tension extant in the hospitalization. This research aimed to uncover the perceptions of the managers of areas and sectors regarding ethical occurrences in the hospital setting. Using a qualitative approach, open questionnaires were administered to 13 managers of sectors in a children's hospital between August and September 2011, giving rise to four analytical categories: Un-noticed conceptualizations in practice; The health team's infractions; Implications for the patients and their companion; and Suggestions and responsibilities. Through the research, reflections and proposals for educational actions were detected, based in ethics and professional confidentiality, with a view to improving hospital attendance.
\end{abstract}

KEYWORDS: Ethics; Hospitalization; Health personnel.

\section{OCURRENCIAS ÉTICAS EN AMBIENTE HOSPITALAR Y LAS PERCEPCIONES DE LOS PROFESIONALES}

RESUMEN: El ambiente hospitalar tiene como particularidad una tensión natural por el hecho de trabajar con la complejidad que abarca la vida y la muerte. Así, se destaca la importancia de cuidados acerca de la ética y del secreto profesional, considerando que descuidarse de esas cuestiones puede agraviar la tensión existente en la hospitalización. El objetivo con esta investigación fue desvendar las percepciones de los superiores de áreas y sectores acerca de ocurrencias éticas en el ambiente hospitalar. Utilizándose de abordaje cualitativo, fueron aplicados cuestionarios abiertos a 13 superiores de sectores de un hospital infantil, entre agosto y septiembre de 2011, los cuales originaron cuatro categorías de análisis: Conceptuaciones despercibidas en la práctica; Transgresiones del equipo de salud; Implicaciones para los pacientes y sus acompañantes; y Sugerencias y responsabilidades. Se vislumbraron con la investigación reflexiones y propuestas de acciones educativas, basadas en ética y secreto profesional, a fin de perfeccionar el atendimiento hospitalizar.

PALABRAS CLAVE: Ética; Hospitalización; Personal de salud.

1 Assistente Social. Especialista em Gestão de Pessoas.

2 Enfermeira. Coordenadora do Serviço de Controle de Qualidade Hospitalar do Hospital Infantil Waldemar Monastier. Mestre em Enfermagem. 


\section{INTRODUÇÃO}

A ética é definida como "o estudo dos juízos de apreciação referentes à conduta humana, do ponto de vista do bem e do mal" ou ainda, como "conjunto de princípios e normas que norteiam o ser humano no que diz respeito à boa conduta"(1:383). Juntamente com o sigilo profissional, o qual caracteriza a ideia de segredo, são assuntos a serem discutidos e trabalhados diariamente em todas as áreas, principalmente em atendimentos individualizados, pois descuidos com atitudes e palavras podem gerar transtornos e consequências para quem oferece e para quem recebe atendimento em saúde. Tendo um hospital como universo desta pesquisa, elenca-se a riqueza de relações humanas existentes no ambiente, tomando-as como ponto primordial de reflexão sobre o cuidado com a ética e com o sigilo profissional; manifestações estas decorrentes do processo de internação, da realização de procedimentos, atendimentos diversos e do próprio sentimento de estar hospitalizado.

O ambiente hospitalar possui, em sua particularidade, uma tensão natural devido ao delicado fato de trabalhar com a vida das pessoas, diante da complexidade que permeia as possibilidades de cura e/ou melhora e que se estende aos temores de um agravamento e morte repentina. As pessoas envoltas por esta particularidade são os usuários do serviço de saúde, caracterizados por serem pessoas fragilizadas que esperam do profissional um gesto humano, de forma a se fortalecer na sua humanidade. "Este fortalecimento pode dar-se através do acolhimento, de um olhar, de uma escuta atenta e de uma palavra"(2:499).

O processo de internação é, de maneira geral, bastante conturbado e se agrava, por exemplo, diante da não preparação da família e do próprio paciente para este momento, ocorrendo quebra de rotina instantânea a qual se manifesta através de ansiedade, angústia e estresse de todos os envolvidos. Neste contexto deve ser

adotada postura ética, de acolhimento, atitude respeitosa para com o usuário entendido como cidadão e não como apenas como um paciente de serviços na área da saúde ${ }^{(3: 31)}$.

Da equipe de saúde espera-se muita paciência, cautela, serenidade e profissionalismo, pois diferente do profissional de saúde, que está familiarizado com o ambiente hospitalar e que conhece a complexidade da área, a família e o paciente não possuem a mesma percepção deste ambiente.
Diante de tal cenário, o objetivo da pesquisa foi desvendar as percepções de chefias de áreas e setores a respeito de ocorrências éticas no ambiente hospitalar. $\mathrm{O}$ estudo se justifica, pois permite reflexões sobre a ética e o sigilo profissional de acordo com práticas diárias; reconhecimento de comportamentos impróprios por parte dos profissionais e, consequentemente, maior cuidado com atitudes e palavras ditas dentro de ambiente hospitalar.

\section{MÉTODO}

O hospital, foco desta pesquisa, é público, especializado no atendimento de crianças e adolescentes. É centro de referência para outros serviços de saúde do Estado do Paraná. Como critério de inclusão para a participação na pesquisa considerou-se: profissional em cargo de chefia de áreas ou setores dentro do hospital; em contato direto com pacientes e acompanhantes e que aceitasse participar da pesquisa mediante a assinatura do Termo de Consentimento Livre e Esclarecido.

A pesquisa, por amostra intencional, de chefias de áreas e setores, possibilitou uma coleta de dados com 13 profissionais representantes dos setores: Centro Cirúrgico, Cuidados Intermediários, Enfermaria, Tratamento Intensivo Pediátrico, Ambulatório, Tratamento Intensivo Neonatal, Centro de Imagem e Emergência, Cozinha/Refeitório, sendo este último referenciado por se tratar de ambiente comum aos profissionais e acompanhantes de pacientes e espaço por onde circulam informações corriqueiras a respeito dos mesmos. As áreas que compuseram a amostra foram: Fisioterapia, Fonoaudiologia, Psicologia, Serviços de Atendimento (Recepção) e Enfermagem. Estes profissionais foram identificados pela letra "C" (colaborador), sendo numerados de acordo com a ordem de entrega dos questionários à pesquisadora.

Este estudo utilizou a abordagem qualitativa de tendência fenomenológica, considerando o método Fenomenológico como aquele que

está dirigido para significados, ou seja, para expressões claras sobre as percepções que o sujeito tem daquilo que está sendo pesquisado, as quais são expressas pelo próprio sujeito que as percebe ${ }^{(4: 93)}$.

A coleta de dados ocorreu entre agosto e setembro de 2011 e como instrumento para a coleta de dados foi utilizado um questionário que continha um caso fictício, de uma ocorrência ética, com questões aber-

Cogitare Enferm. 2012 Out/Dez; 17(4):655-60 
tas referentes ao mesmo. O propósito foi conhecer a opinião da chefia a respeito do caso apresentado, sua relação com a ética profissional, sua familiaridade com o cotidiano e sugestões para a temática. Os dados foram analisados a partir da análise de conteúdo ${ }^{(4)}$.

O projeto de pesquisa recebeu parecer favorável do Comitê de Ética em Pesquisa da Secretaria de Saúde do Estado do Paraná / Hospital do Trabalhador, sob o processo n. 327/2011.

\section{RESULTADOS}

Como resultado da pesquisa obteve-se quatro categorias de análise, que traçam o percurso das possíveis ocorrências éticas em ambiente hospitalar.

$\mathrm{Na}$ categoria: Conceituações despercebidas na prática, à ética foi visualizada como:

[...] conjunto de valores morais e princípios que norteiam a conduta humana na sociedade. A ética serve para que haja um equilibrio e bom funcionamento social, possibilitando que ninguém saia prejudicado. (C1)

A reflexão diante de ocorrência ética e possibilidade de existirem prejudicados destaca a importância do cuidado e da atenção referente à conduta no trabalho realizado diante do delicado momento de hospitalização. A rotina profissional, envolta pela multiplicidade de tarefas, pode ser um facilitador ou dificultador de práticas que invadem a privacidade de pacientes e acompanhantes.

Ainda na mesma categoria sobre conceituações, para os participantes da pesquisa o sigilo profissional é uma:

[...] característica fundamental no ambiente de trabalho. (C1)

[...] deve ser mantido e a informação sobre paciente deve ser compartilhada apenas para discussão de melhorias ao paciente entre a equipe. (C9)

Tal situação poderia ser avaliada como medida ideal, não fosse a extensão de informações para além das discussões profissionais.

Outra categoria analisada foi: Infrações da equipe de saúde. Os entrevistados verbalizaram problemas de comunicação como meio para deturpação de informações, as quais movimentam boatos infundáveis e especulações corriqueiras e, em muitos casos, repleta de pré-julgamentos. Respostas desta natureza foram:
Cada um ouve o que quer e fala o que convêm. (C12) [...] falha na comunicação; entendimento errado do fato; distorção da história passada; atitudes impulsivas no ambiente hospitalar; desrespeito com a vida do paciente e do familiar. (C13)

Tais situações, associadas à falta de sigilo, podem ocasionar danos físicos, psicológicos e sociais, resultando em consequências graves para quem oferece e para quem recebe o atendimento no ambiente hospitalar. Sobre os motivos, que levam os profissionais a se envolverem em situações com estas características, podem ser provenientes de uma questão cultural, fundada na necessidade de saber o que está acontecendo na vida de outras pessoas. Afirmações neste sentido foram:

Há muitos boatos e especulações sobre alguns pacientes internados. (C12)

Infelizmente situações como estas [boatos, informações sem fundamento] acontecem e com uma certa frequência. (C4)

Para os profissionais faltam orientações e informações sobre um determinado caso e/ou assunto, tornando-se grande motivador de especulações:

Quando há falta de informação da equipe envolvida na assistência incentiva a divulgação desses boatos. (C5)

A terceira categoria: Implicações para os pacientes e seus acompanhantes é consequência do que se evidenciou na categoria anterior. Como afirma um participante:

A vida pessoal, os problemas, a história dos pacientes e seus familiares pertencem a eles. (C12)

Os transtornos gerados, especialmente ao acompanhante da criança internada, podem incorrer desde falsas expectativas, revoltas e principalmente, a exposição de suas vidas de forma desnecessária; questões agravadas por fazerem parte das particularidades do ambiente hospitalar.

A clareza de informações e a necessidade de verificar as reais circunstâncias de cada caso atendido são informações relevantes, destacadas pelas chefias, como meio para se evitar especulações desnecessárias. Isto fica evidenciado na fala:

A vida do paciente não pode ser boato pelos corredores do hospital, ou tratada nas ruas, fora do ambiente hospitalar. (C3) 
A quarta categoria: Sugestões e responsabilidades no trato da ética foi identificada, como busca para soluções efetivas aos problemas éticos:

É hora de educar os servidores [...] a equipe que é responsável pelos cuidados dessa criança deve ter a preocupação tanto com a assistência como com o bem estar dessa criança. A ética nos mostra que qualquer comentário referente ao paciente deve ser mantido pela equipe e não ser informado ao hospital todo, caso contrário poderá vir gerar transtornos para a família. (C9)

A proposta de eventos sobre a temática foi apresentada como meio de viabilizar a sensibilização dos profissionais. Um participante diz:

Cursos de capacitação trazendo exemplos de casos verídicos para que haja reflexão dos participantes. (C12)

A utilização das rodas de conversas foi outra sugestão, que se configurou em espaço oportuno para constantes discussões e reflexões sobre casos, os quais possibilitariam o direcionamento para a necessidade da conduta profissional adequada, principalmente no que trata do sigilo profissional. Também fica evidente a responsabilidade da gestão, tal como expressa um participante:

[...] a gestão da instituição hospitalar deve prezar por sigilo e descrição na condução dos casos. (C5)

Esta afirmação mostra que a gestão do hospital pode aprimorar a responsabilidade compartilhada, de tal modo que todos os profissionais sejam responsáveis por condutas profissionais éticas.

\section{DISCUSSÃO}

O cotidiano atribulado de um hospital envolve os profissionais em atividades diversificadas e complexas, as quais podem incorrer em falta de respeito à identidade, intimidade e privacidade de pacientes e de acompanhantes. Possíveis infrações éticas de forma direta ou indireta poderão ocasionar implicações físicas, psicológicas ou sociais, logo é também de responsabilidade de chefias comprometerem-se em promover ambientes seguros e manter constante reflexão com as equipes sobre a temática ética nas práticas diárias.
A ética se propõe compreender critérios e valores os quais orientam o julgamento da ação do homem diante de suas múltiplas atividades, principalmente na vida associada e no trabalho ${ }^{(5: 76)}$.

\section{Infelizmente}

a rotina hospitalar tornou-se espaço para ocorrências éticas, seja no atendimento prestado diretamente ao paciente, seja pela prática clínica ou qualquer processo de trabalho que expresse fenômenos da saúde e da doença, tanto na singularidade quanto na coletividade do sujeito ${ }^{(6: 10)}$.

Os laços criados com as equipes são oportunidades para aquisição de conhecimentos sobre os cuidados com a criança, a construção coletiva de práticas e permitir o estabelecimento de relações mais simétricas entre os envolvidos $^{(7)}$. Contudo, nas ações de assistência, individual ou coletiva, o vínculo entre profissionais, pacientes e acompanhantes pode resultar em abertura de detalhes da vida pessoal de ambas as partes. Neste momento, informações e situações particulares e sigilosas podem ser expostas, mas devem ser mantidas entre as partes como referiam os participantes desta pesquisa.

A inexorável formação de vínculo em ambiente hospitalar propicia apoio dos pais ao cuidado, promoção para o preparo da alta hospitalar, redução do impacto psicológico da internação com vistas à integralidade da assistência, diálogo e apoio ${ }^{(8)}$, mas não justificado como meio de conversas inoportunas entre os não envolvidos no assunto permeando ambientes e espaços do hospital, tais como enfermarias, refeitório, corredores e outros.

Um dos aspectos desta problemática está na formação de profissionais, com destaque para a área da saúde, que não tem acompanhado a temática ética no contexto de necessidades da sociedade, uma ética construída e exercitada. Isso ocorre devido ao maior interesse nos aspectos técnicos da assistência, em detrimento daqueles que ferem a dignidade da pessoa $^{(5)}$. Há danos ao paciente e acompanhante, que demonstram constrangimento, vergonha e embaraço diante de invasão de privacidade. É dever de o profissional exercer o cuidado respeitoso, este como direito fundamental; sendo a atenção e assistência isentas de infração ou negligência de outros direitos da pessoa. O autor refere-se a Kant quando escreveu que o cuidado sem o respeito é cego; o respeito sem o cuidado é vazio. Já o cuidado respeitoso constitui-se de atitude moral e absolutamente necessário à bioética atual ${ }^{(9)}$.

Cogitare Enferm. 2012 Out/Dez; 17(4):655-60 
Para isso cabe ao profissional de cada área (Serviço Social, Psicologia, Enfermagem, entre outras) avaliar a necessidade de repassar informações, por vezes sigilosas, a toda a equipe envolvida com o caso, com atitudes de respeito à individualidade. É inerente ao profissional a tolerância, a solidariedade, a tranquilidade para informar e confortar aqueles que estão em estresse pela doença e, ou internação. Nesta perspectiva, atuar em contextos de saúde, seja ele em qualquer grau de complexidade, requer do profissional

constante revisão sobre o modo que esta a serviço do outro, o que exige discussão sobre os pressupostos tradicionais e atuação que vai além das práticas tarefeiras, dando assim abertura ética para uma nova atitude para com o usuário, paciente ${ }^{(10: 702)}$.

Ao adotar posturas que transmitam segurança, apoio e confiabilidade, buscando realizar seu trabalho da melhor forma possível e esclarecendo dúvidas sobre cada caso os profissionais se defrontaram com o fortalecimento da humanização, facilitando por sua vez as intervenções e atendimentos aos pacientes internados. Os entrevistados ofereceram sugestões no trato com a ética, dentre elas propõem melhorar o fluxo de informações de pacientes no hospital e a formação de uma comissão de ética na instituição para discussão sobre estas situações. Sobre a melhoria na comunicação a instituição, local da pesquisa, já possui um projeto com este objetivo. E se tratando de uma comissão de ética, em fevereiro de 2011 foi instituída uma Comissão de Ética Médica.

Além da responsabilidade de cada profissional, deve-se "realizar constantes avaliações do cuidado prestado vislumbrando ressaltar que os princípios éticos sempre devem direcionar a profissão"(11:467). Tratando-se de orientações em práticas de educação em serviços, estas devem ser embasadas em casos reais da rotina do serviço, objetivando reflexão e mudança de conduta.

\section{CONSIDERAÇÕES FINAIS}

O objetivo da pesquisa de conhecer as percepções das chefias a respeito de ocorrências éticas no ambiente hospitalar foi atingindo. Os resultados apontaram novas reflexões e desafios partindo das próprias chefias. Além disto, surgiram sugestões para trabalhar a temática, as quais vislumbram ações que impulsionem discussões entre os profissionais. Sendo este o objetivo da pesquisa, afirma-se que o alcance do mesmo ocorrerá de forma paulatina na instituição, considerando que são realizadas ações direcionadas ao debate sobre o cotidiano e a ética profissional. Essas decorrentes da necessidade e da confirmação de que existem ocorrências éticas e que estas precisam ser trabalhadas e modificadas na rotina hospitalar.

Tratando-se de uma temática fundamental para a qualidade do atendimento, vislumbram-se novas pesquisas que abordem a ética como tema central de discussão na rotina profissional. Essas que considerem a percepção não apenas das chefias, mas também dos colaboradores envolvidos diretamente com a assistência ao paciente; que busquem compreender as representações sociais dos próprios pacientes e acompanhantes sobre a ética em ambientes de saúde. Ainda é importante compartilhar experiências de práticas já desenvolvidas em serviço e estudos de casos que possam inspirar a discussão sobre a temática.

\section{REFERÊNCIAS}

1. Ferreira ABH. Mini Aurélio: o dicionário da língua portuguesa. $6^{\text {a }}$ ed. rev. atual. Curitiba: Positivo. 2010.

2. Martinelli ML. O trabalho do assistente social em contextos hospitalares: desafios cotidianos. Serv. Soc. Soc. [Internet] 2011;107 [acesso em 22 mar 2012]. Disponível: http://www.scielo.br/scielo.php?script=sci_ arttext\&pid=S0101-66282011000300007\&lng $=$ pt\&nrm =iso. ISSN 0101-6628. http://dx.doi.org/10.1590/S010166282011000300007.

3. Fortes PAC. Ética, direitos dos usuários e políticas de humanização da atenção à saúde. Saude soc. [Internet] 2004;13(3) [acesso em 22 mar 2012]. Disponível: http:// dx.doi.org/10.1590/S0104-12902004000300004

4. Martins J, Bicudo MAV. A pesquisa qualitativa em psicologia: fundamentos e recursos básicos. São Paulo: Moraes, 2006.

5. Souza ML, Sartor VVB, Prado ML. Subsídios para uma ética da responsabilidade em Enfermagem. Texto Contexto Enferm. [Internet] 2005;14(1) [acesso em 12 abr 2011]. Disponível: http://www. scielo.br/scielo.php?script $=$ sci_arttext\&pid $=\mathrm{S} 0104-$ 07072005000100010\&lng=en

6. Vieira AN, Silveira LC, Franco TB. A formação clínica e a produção do cuidado em saúde e na enfermagem. Trab. Educ. Saúde. [Internet] 2011;9(1) [acesso em 21 mar 2012]. Disponível: http://www.scielo.br/scielo.php ?pid=S198177462011000100002\&script=sci_arttext 
7. Alves CA, Deslandes SF, Mitre RMA. Desafios da humanização no contexto do cuidado da enfermagem pediátrica de média e alta complexidade. Interface - Comunic., Saude, Educ. [Internet] 2009;13(supl.1) [acesso em 21 mar 2012]. Disponível: http://www.scielo. br/pdf/icse/v13s1/a10v13s1.pdf

8. Couto F F, Praça NS. Preparo dos pais de recémnascido prematuro para alta hospitalar: uma revisão bibliográfica. Esc. Anna Nery. [Internet] 2009;13(4) [acesso em 21 mar 2012]. Disponível: http://www.scielo. br/pdf/icse/v13s1/a10v13s1.pdf

9. Dall'Agnol D. Cuidar e respeitar: atitudes fundamentais na bioética. Bioethicos. 2012;6(2):133-46.

10. Carvalho LB, Bosi MLM, Freire JC. Dimensão ética do cuidado em saúde mental na rede pública de serviços. Rev. Saúde Públ. [Internet] 2008;42(4) [acesso em 22 mar 2012]. Disponível: http://www.scielo.br/scielo. php?script $=$ sci_arttext\&pid=S0034891020080004000 $17 \& \operatorname{lng}=$ pt\&nrm $=$ iso

11. Cerri A, Roehrs H, Crozeta K, Sarquis LMM, Palu L. Problemas éticos no cuidado ao paciente crítico. Cogitare enferm. [Internet] 2011;16(3) [acesso em 22 mar 2012]. Disponível: http://ojs.c3sl.ufpr.br/ojs2/index. php/cogitare/article/download/24222/16231 